\title{
Cultural Difference in the Teaching of English Lexicon
}

\author{
Jiaoli Chen \\ Sichuan College of Architectural Technology, Deyang, Sichuan, China
}

Keywords: English Lexicon, Cultural difference, English teaching.

\begin{abstract}
The purpose of language learning is to communicate. Undoubtedly, lexical teaching also serves this purpose. The social communication among human beings is not only a language phenomenon, but also a cross-cultural phenomenon. We must first understand what culture is before we contrast the two kinds of cultural communication. The narrow sense refers to literature, music, art, etc, while its broad sense is a sociological term, which refers to the total pattern of special faith, habit, system, target and technique in a certain society. However, the cultural difference between Chinese and English is normally not available to students.
\end{abstract}

\section{Introduction}

Geertz and Douglas claim: "Cultures are systems of symbols, and lexicon is only one of the symbolic systems in this network."[1] This definition entails that interpreting the meaning of English lexicon requires knowing the cultural difference in which it is embedded. As a second language leaner, we must understand the characteristics of the culture to understand the lexical structure context.

However, in some schools, the cultural difference between Chinese and English is always neglected, and teachers pay little attention to it. They do not understand the importance of cultural difference in their teaching process. As a result, the lexica that students learned are just literally meaning and they cannot use them correctly in a real situation. Therefore, we can see that acquiring the knowledge of cultural difference is very important in the teaching of English lexicon.

\section{The Main Problems in English Lexical Teaching}

\subsection{The Cultural and Social Factors Neglected}

Lexicon is a basic unit of sentence. In someone's view learning English is to study the lexica and grasp its basic pronunciation, writing, and meaning, as well as grasp some basic grammars, and know how to link each lexicon and phrase. However, it is impracticable to communicate with foreigners if they neglect cultural factors.

Traditionally, in teaching English lexicon, the form of English has been emphasized. It results that students with good mastery of English grammars and large vocabulary may not communicate appropriately in English. To cross cultural boundaries, English lexical learners need to develop the flexibility of communication. Different cultures have different expressions in their lexica. For example, "Are you married?", "What's your job?". These are common greetings in the Chinese context. But if one asks American friends the same questions, the original illocutionary force does not exist. The American friends may feel confused at this "greetings" because they think these "greetings", such as marriage, jobs, and salary, are their private. Cultural difference between Chinese and English is reflected in this example.

\subsection{Limited English Materials}

Most of the students have many words and phrase filled in their minds after 6 years of English learning in their middle school, but they cannot use correctly in a real situation, because the English materials they have learned are separated from cultural and social factors. 
In China social factors are always neglected in the teaching of English lexicon. The reason is that the development of English lexical teaching is mainly restricted by the theory of language development. Lexicon itself is the research of traditional lexical teaching. Therefore, teachers have not put the English lexical teaching and the knowledge of cultural difference in the equally important position. Meanwhile, the English materials are always influenced by social climate in China, we can find that most English materials students use are some short stories, dialogues, poets and prose. Although the type of materials is varied, the content is unitary and colorless. Some English materials are even influenced by social and political factors; they mainly describe some heroic characteristics of workers or farmers. As a result what the students learned are English, but their ideological connotations are Chinese culture, and lexicon and culture are separated. Therefore, they always use lexica inappropriately.

\section{Relying too much on English Lexical Teachers}

\subsection{Teaching Literally}

The ability of communication is the ultimate goal of English lexical teaching. It doesn't mean people have ability of communication if they have lexical ability. However, teachers usually pay more attention to forms and grammatical structures of lexica and cultivating students to make sentences conforming to grammatical principles. In this way they neglect language environment, especially the cultural difference in lexica, so students can hardly understand how to use suitable lexica in some places. As we know the majority of Chinese learn English from the beginning of middle schools. Some primary schools just set up the English lessons in recent years. During 6 years' process of English study in high school, the writer has found that all teachers have a common characteristic in teaching: words and phrases first, then texts and some practices. They follow three principles to teach words: sound, form, meaning, and among them "meaning" is just a superficial sense of a word itself. Whereas, the teaching of text is also over-emphasizing the rules of language--how each word forms a sentence according to grammatical rules and what is the function of some words and phrase in this sentence.

\subsection{Limited Cultural Knowledge of Teachers}

Some students only learn the knowledge taught by their teachers and believe what the teachers taught are all correct. However, some English lexical teachers have limited knowledge of culture between Chinese and English. The teachers are in an authoritative position because they are believed to have more knowledge contained in the information they provide to the learners. Although the teachers are often more linguistically competent than their students, they may not have enough knowledge about cultural difference between Chinese and English. At this stage, many Chinese English lexical teaching teachers have had few opportunities for overseas experience and they do not have close contact with native speakers of English, so their knowledge about English culture is limited. Furthermore, teachers, like students, may have misconceptions or misunderstandings about cultural difference. If English lexical teachers' misinterpretations of English culture are taken as an authoritative source of the students' developing knowledge, then there is a danger that wrong perception of lexica will occur. This, of course, does not mean the teachers' role is unimportant. The point is that the teachers' knowledge about cultural difference plays an important role in enriching the students' knowledge about cultural difference between Chinese and English.

\subsection{The Importance of Cultural Difference between English and Chinese in English Lexical Teaching}

The cultural knowledge about an English lexicon is related to its connotation, rather than literal meaning. Because literal meaning refers to basic or obvious meaning and it is not related to culture. If students cannot distinguish the cultural difference of lexicon, they will make a serious mistake on language using. For instance: what's the meaning of "green with envy" in English? When people are envy, do their facial expressions really become green? So we know the difficulties that students meet 
are not caused by their knowledge when they learning the target lexicon, but by the cultural difference.

The view of cultural difference between Chinese and English views is reflected in English lexicon. Different cultures have different ways of dividing the color spectrum, for example, illustrating different lexicon views on what color is and how to identify the emotional diversity in English and Chinese. Sometimes they take a polite word for a vicious slander, which may cause unpleasant feelings on speakers or both parties, for example, the words "politician" and "statesman". Dose politician really means someone who deals with political affairs? Speaking reversely, how can we translate "zheng zhi jia" in Chinese into English? There may be some students who translate it into "politician", but it is unsuitable, for "politician" has a strong derogatory emotion in United States, and it is easy to cause scorn by others. In US "politician" is a person who makes trick in order to take personal interest. Meanwhile, this word has the meaning of a "smart and tactful person", which means a person is confident and experienced when doing things or talking to others. In Chinese the word "zheng zhi jia" should translate into "statesman", for it is very appropriate in both British English and American English. Because "statesman" mainly expresses those who are good at managing a nation, and people usually call prestigious officials "statesman". Therefore, students must get clear ideas of cultural emotion first before learn a new lexicon.

\subsection{Promoting Self Lexical Study by Knowing Clear Cultural Difference}

Because all English lexical teachings are limited to certain knowledge it is unrealistic for English lexical learners to learn a new culture in the same way as they have learned their own culture. The basic factor in English lexical teaching is the clear cultural difference, adding clear content about English culture to English lexical teaching may be less time-consuming and more efficient than leaving this knowledge to be gained through a long process of learning English lexica. Loew et al strongly suggest: "Culture should be the central part of the second language course content."[2] They believe that the skill and knowledge acquired while developing a deep understanding of the cultural difference can be expanded by students. Without clear understanding about cultural difference between Chinese and English at the beginning, such an exploration is impossible. Therefore, the teaching of English lexicon should follow this principle.

\section{The Correct Methods of English Lexical Teaching}

\subsection{Integration of Culture and Lexicon}

Extra effort to teach culture is not required in regard to organizing an additional course component, etc. In other words, there is no particular or obvious place purposefully given to the teaching of English culture. The whole process of lexical teaching is left to take care of culture. The teaching of culture and the teaching of lexicon are naturally integrated by focusing on language use in communication.

As we know culture is relevant to lexicon, but the one that has the most immediate importance for students who learn English lexicon is to combine the cultural knowledge and lexical learning. An understanding of culture is needed in order to use the patterns of address in a lexicon properly, for instance, as well as to know whom to avoid and when to remain silent. So the absence of certain objects, events, concepts or states in English culture will naturally result in the absence of the necessity to refer to them.

\subsection{Communicative Lexical Teaching}

Compared with cultural studies which we have examined in the previous section, we might say the communicative movement represents a milestone in teaching lexicon and culture English culture is taught through teaching lexical learners to behave, in other words, to use the lexica for communication. According to Byrnes "the major contribution of the concept of communication competence is to rejoin lexicon and culture in teaching by emphasizing communication."[3] With the preference for learning by doing in communicative lexical teaching, the barriers between lexical 
learning and cultural learning have been broke down. The communicative has strengthened the previous assertion that lexicon and culture are inseparable and hence that the teaching of culture is an indispensable part of language teaching. At the theoretical level, the debate about communicative competence has assured the importance of cultural elements in lexical teaching. At the practical level, lexicon and culture are taught together by focusing on the purpose for communication.

\subsection{Increasing the Culture Awareness of Students}

The teaching of English lexicon inevitably involves the teaching of English culture. This always raises political questions, as well as cultural questions. Teachers with a background in linguistics, language and cultural studies may and do formulate various solutions to the questions of the proper, educational association of the lexica and culture. Bearing the students' internal change in mind and acknowledging English as source of cultural understanding and a means for English lexical teaching, English lexical teachers must reconsider the objectives of English culture in educational institutions at all levels. The major concern must be to seek objectives appropriate to majority of English lexical students. Teachers should merge the cultural difference between Chinese and English into English lexical teaching, such as the greeting.

\subsection{Using a Variety of Ways to Absorb and Experience English Culture}

Teachers can use a variety of ways to absorb and experience the difference of English culture from Chinese, such as collecting some articles and pictures of English countries, so as to let students understanding the English art, history and local conditions; at the same time the English films and TV can bring direct feelings to students so that they can imperceptibly by what they see and hear, and teachers also can recommend some simple books which reflect the English culture, thus increasing students' understanding about the use of English lexicon in certain places. Outside the class teachers can offer some English cultural lectures. As we have argued, cultural difference takes place in situations of negotiating meaning and culture in the English lexica. Because English lexicon can reflect in English dialogue, cultural learning through English lexical textbook might also be seen as a process of dialogue in which students negotiate meaning and culture vicariously with the author of the textbook and its cultural content. However, this is mediated in the classroom with a teacher who manages the way in which the students see the cultural difference in the textbook. The teacher may also thereby mediate ways in which students see themselves.

\section{Summary}

Lexicon is not only a basic unit of sentence, but also an important factor in communication. Whereas, culture and lexicon cannot be separated, if students want to learn English lexicon correctly, they should learn cultural difference between Chinese and English. Because cultural difference is an important factor, teachers should not just teach words only literally, they should give much priority to English lexical teaching. Teachers must distinguish the lexical cultural difference between Chinese and English, so as to let students really understand the connotation of English lexicon in the process of English lexical learning, and use the lexica properly in communication, reaching the real purpose of English lexical teaching.

\section{Acknowledgement}

If you follow the "checklist" your paper will conform to the requirements of the publisher and facilitate a problem-free publication process.

\section{References}

[1] H.D Brawn, ed., Principles of Language Learning and Teaching (Shang Hai: Foreign Language and Research Press, 2012), 121.

[2] Shen Chen. Culture Teaching in Foreign Language Education. Beijing: Beijing Language and Culture University Press, p.66.

[3] Ibid., 87. 